\title{
Efficiency of FTO/Graphene-based Dye-Sensitized Solar Cell
}

\author{
Awodugba, Ayodeji Oladiran \\ Department of Pure and Applied Physics, Ladoke Akintola University of Technology, \\ Ogbomoso, Nigeria \\ aoawodugba@lautech.edu.ng \\ Corresponding author \\ Yusuf, Gbadebo Taofeek \\ Department of Science Laboratory Technology (Physics unit) \\ Osun State Polytechnic, Iree, Nigeria \\ taofeeky001@gmail.com
}

\begin{abstract}
The focus of this research is to improve the performance of dye-sensitized solar cells (DSSC) through the adoption of high-quality FTO thin films and incorporation of graphene with DSSC photoanode to enhance its electrical transport. In this research, nanostructured FTO films were first grown with homemade Streaming Process for Electroless and Electrochemical Deposition technology (SPEED) using Tin (II) chloride dihydrate and ammonium fluoride and other chemical formulations. The FTO structural property was measured by X-ray diffraction (XRD); the films' optical property was determined with transmittance spectra to curve over the wavelength range of 200-1000 nm measured with a spectrophotometer while scanning electron microscope (SEM) was used to determine the morphological properties of the samples. The electrical transport was evaluated by Hall Effect measurements at room temperature with a four-point probe. The FTO samples with the best structural, optical and electrical properties were employed as electrodes and counter electrodes of DSSC along with titanium dioxide. Thus, effect of graphene on the efficiency of DSSC was investigated. It was shown that a graphene-based DSSC showed an efficiency of $7.98 \%$ which is slightly higher than that of DSSC prototype without graphene (6.02\%). The higher efficiency obtained with graphene can be credited to the ultrahigh surface area and thermal conductivity of graphene which tend to enhance the charge mobility and photovoltaic performance of DSSC. More research is however required to determine the exact amount of graphene that could achieve optimal DSSC performance. Further studies will also offer an adequate clarification for starting point of the better incorporation of graphene in DSSCs.
\end{abstract}

\section{Keywords: Graphene, Dye-sensitized solar cell, Efficiency, FTO, SPEED}

\section{Introduction}

Dye-sensitized solar cell (DSSC) is widely researched due to its low cost, simple preparation techniques and non-toxic [1-2].Considerable efforts have been made so far to enhance the energy conversion efficiency, long-term stability and cost-effectiveness [3-5] of the DSSC. Efforts are still going to further enhance the performance of DSSC [1-6].

Among the DSSC components widely studied is photoanode with well optimized TCO semiconductor [7]. There are a number of factors that make TCO an excellent candidate for DSSC application. Some of them are possession of high optical transparency typically above 80\% [7], possession of excellent electron transport, large band gap, stability, good conductivity and high affinity for sensitizer loading [8]. Earlier, some wide gap TCOs such as titanium oxide $\left(\mathrm{TiO}_{2}\right)$, undoped tin oxide $\left(\mathrm{SnO}_{2}\right)$ and zinc oxide $(\mathrm{ZnO})$ have been having been employed as DSSC photoanode [8]. Optical and electrical properties are two important TCO requirements which cannot be easily increased simultaneously; attempt to increase optical property may degrade the electrical property [10]. Therefore, the present challenge is how optical and electrical properties could be 
increased without tradeoff of any one of them. This challenge has been overcome in this research using a promising technique known as "Streaming Process for Electroless and Electrochemical Deposition technology" commonly referred to as SPEED technique and its chemical formulation (www.sisomtf.com). SPEED is a technique which could rapidly coat a substrate with nanoparticlebased films with minimal scattering of electron carriers. Its home set up approach was employed in this research though, but the result was yet promising due to its nature of excellent chemical formulation as well as ease of optimizing multiple key controlling parameters. Previously, this technique has been employed in fabricating high-quality FTO films materials [16-17; 48-50]. Hence, it will be used in this research to grow high-quality FTO thin films for DSSC application. The resulting FTO films were then incorporated as DSSC photoanode along with $\mathrm{TiO}_{2}$ and graphene.

\section{Experimental}

\section{Optimization of FTO key deposition conditions/parameters}

High-quality FTO films for DSSC photoanode application were first grown while optimizing the key deposition controlling parameters. One deposition parameter was kept fixed during the experiment and its effect was assumed negligible during the investigations. It is a very difficult task to adjust all parameters simultaneously and arrive at a common deposition procedure (condition) for the films. Hence to identify the best deposition conditions, each parameter was optimized individually. Table 1 shows the details of optimization of FTO key controlling parameters. These ranges of values were obtained from theories and previous researchers on FTO [16].

\subsection{Preparation of FTO materials}

Having achieved the best deposition conditions discussed in the previous section, high-quality FTO films were then grown from these conditions using a homemade SPEED technique (fig. 1).The FTO films have been previously grown with original SPEED technique shown in fig. 2 which is more simple, easy and quick to use.

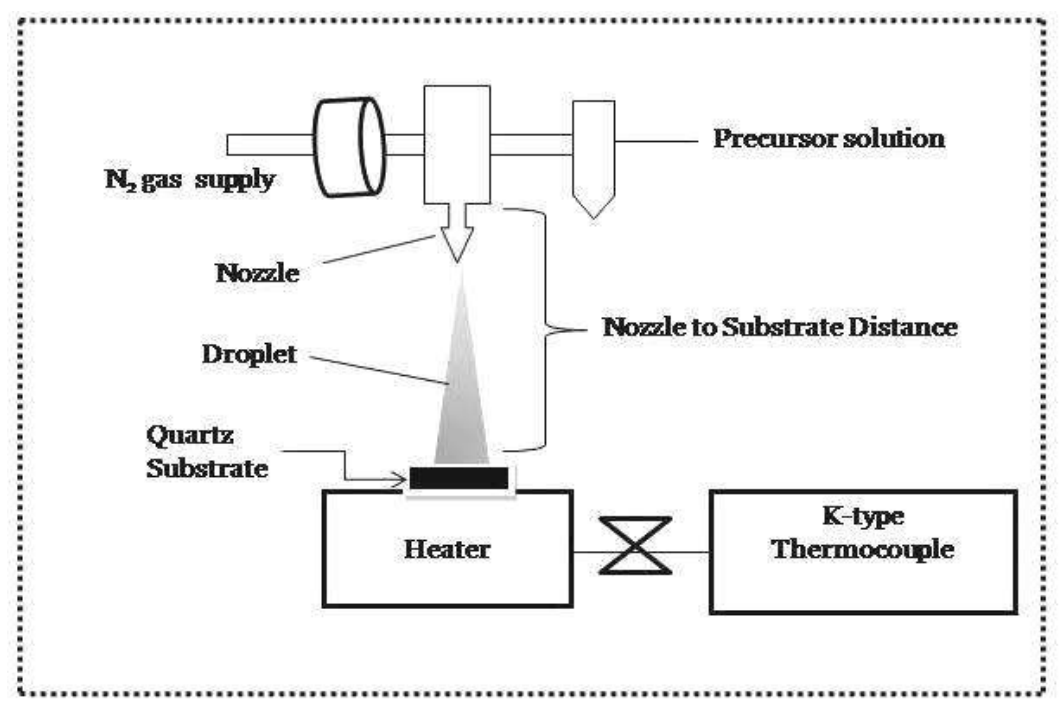

Fig. 1: Schematic diagram of homemade SPEED set up 


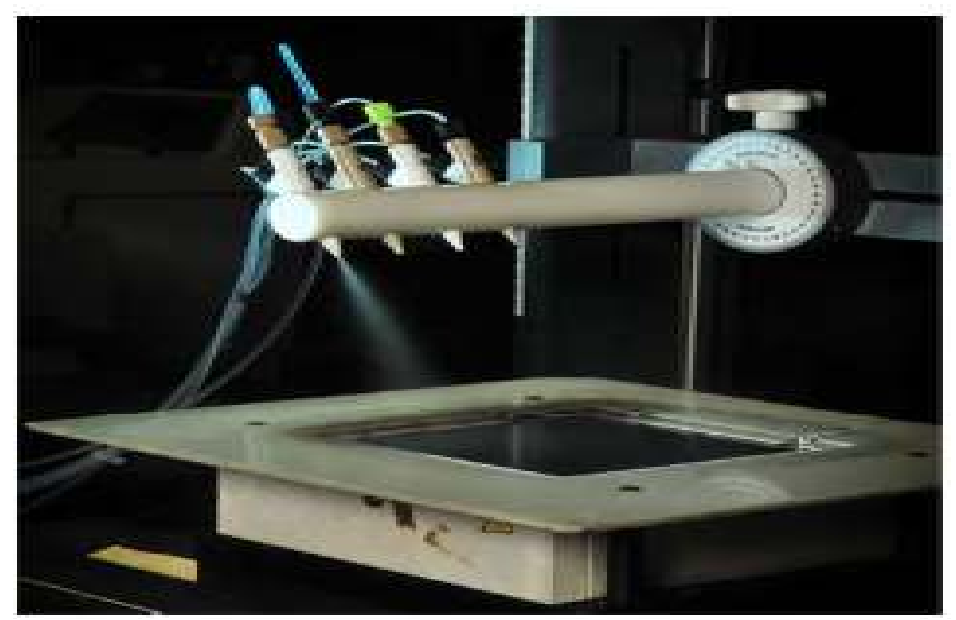

Fig. 2: Photograph of original SPEED spray head [16-18; 48-50]

The adopted chemical formulation belongs to SISOM SPEED LLC (www.sisomtf.com) [16]. Tin (II) chloride dehydrate was used as starting precursor. The precursor was doped with $50 \%$ ammonium fluoride $\mathrm{NH}_{4} \mathrm{~F}$ to enhance its electrical properties. "The precursors were dissolved in a mixed solvent of water, ethanol, isopropanol, and methyl propanol" the detail of chemical formulation and the experimental procedure can be seen in [16].The water acted mostly as solvent and oxygen source, whereas ethanol, isopropanol, and methyl propanol acted mostly as complexing agents for Sn ions. The complexing capability of the mixed solvents was used to control the solution stability and shelf life [16]. The deposition conditions adopted are shown in table 2, that is, substrate temperature (460 $\left.{ }^{\circ} \mathrm{C}\right)$, flow rate $(1.2 \mathrm{ml} / \mathrm{min})$, the ratio of $\mathrm{F} / \mathrm{Sn}$ (0.95atomic ratio), and the substrate to nozzle distance (SND) $(30 \mathrm{~cm})$ and so on.

"The precursor solution was put into droplets form by an ICP/MS nozzle, which was specified by the manufacturer to produce droplets in the size range $5-15 \mu \mathrm{m}$ and these droplets were sprayed onto the heated substrate; before deposition, the $5.0 \mathrm{~cm} \times 5.0 \mathrm{~cm}$ substrates were cleaned thoroughly with industrial soap, rinsed with deionized water followed by acetone, then rinsed again with deionized water, and hot-air dried" [16].

Table 1: Optimization of key controlling parameters

\begin{tabular}{|c|c|c|c|c|c|c|c|}
\hline Parameters & Range & 1 & 2 & 3 & 4 & 5 & 6 \\
\hline F/Sn atomic ratio (mole) & $0-1.5$ & 0 & 0.35 & 0.55 & 0.75 & 0.95 & 1.15 \\
\hline Flow rate $\mathrm{ml} / \mathrm{min}$ & $0.6-2.4$ & 0.6 & 1.2 & 1.8 & 2.4 & & \\
\hline NSD (cm) & $25-32$ & 24 & 27 & 30 & 33 & & \\
\hline Water addition (\%) & $0-1.5$ & 0 & 0.5 & 1.0 & 1.5 & & \\
\hline Precursor qty $\left(\mathrm{cm}^{3}\right)$ & $15-45$ & 10 & 20 & 30 & 40 & & \\
\hline Substrate temp $\left({ }^{\circ} \mathrm{C}\right)$ & $400-500$ & 400 & 420 & 440 & 460 & 480 & 500 \\
\hline Ageing (hours) & $6-24$ & 6 & 12 & 24 & & & \\
\hline
\end{tabular}

Table 2 shows the best deposition conditions obtained after several optimization experiments and trials. These conditions were utilized to deposit high-quality FTO samples for DSSC photoanode component. This is fully discussed in the next section. 
Table 2: Parameters and deposition conditions for the best FTO material

\begin{tabular}{lll}
\hline & Parameters & Deposition conditions \\
\hline 1. & Starting precursor & $\mathrm{SnCl}_{4}$ doped with ammonium fluoride \\
2. & Flow Rate & $1.2 \mathrm{ml} / \mathrm{min}$ \\
3. & Substrate temperature & $460{ }^{\circ} \mathrm{C}$ \\
4. & F/Sn concentration & $0.95 \mathrm{atomic}$ ratio \\
5. & Substrate to Nozzle Distance (SND) & $30 \mathrm{~cm}$ \\
6. & Deposition Time & $30 \mathrm{minutes}$ \\
7. & Films thickness & $150 \mathrm{~nm}$ \\
8. & Aging of precursor & $12 \mathrm{hrs}$ \\
9. & Pressurized & $0.75 \mathrm{bar}$ \\
\hline
\end{tabular}

\section{Characterization of FTO film samples}

X-ray diffraction (XRD) system at $2 \theta$ values from 20 to 80 degrees with $30 \mathrm{kV}, 40 \mathrm{~mA}, \mathrm{Cu} \mathrm{Ka}$ radiation $(\lambda=0.1540598 \mathrm{~nm})$ was employed to record the films crystallinity.

Scanning electron microscopy (SEM) was used to characterize the particle morphologies using a Zeiss Ultra 55 SEM at $5 \mathrm{kV}$.

A 5000 Digital Atomic force microscopy (AFM) Instruments model system in a contact mode was used to study surface topology.

A Perkin-Elmer Lambda 900 spectrophotometer collected transmittance spectra $T$ over the wavelength range $200-1000 \mathrm{~nm}$. The absorption coefficient was calculated according to equation 1 . $\alpha=(1 / \mathrm{d}) \ln (1 / T)$

The optical band gap of the material was deduced from the absorption coefficient spectrum. The resistivity, mobility, and carrier concentration were evaluated by Hall Effect measurements at room temperature in a Van der Pauw [21] four-point probe configuration.

\section{Results and Discussions}

\section{FTO's optical and electrical properties}

The X-ray diffraction of FTO grown with the key controlling parameters of table 1 is shown in fig. 3. The FTO film shows the most obvious reflection at (200) orientation. Other discernible orientations are $110,211,310$ and 301 planes. This implies that the FTO film is highly crystalline with tetragonal structure [22]. Other peaks traceable to another crystal or phase are not discernible in the structure.

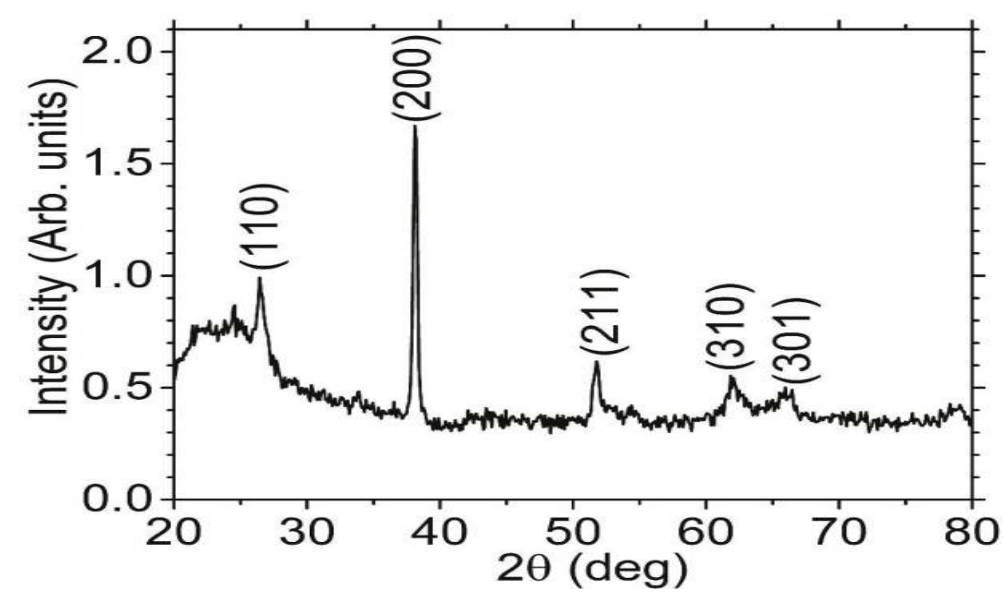

Fig. 3: X-ray diffraction of the FTO films or best FTO materials 
Fig. 4 shows the transmittance curve for FTO film deposited from the highly optimized and key deposition parameters shown in table 1 . The measurement was taken in the wavelength range 250 to $1000 \mathrm{~nm}$. From the scanning electron microscopy (SEM) and AFM (fig.4). This structure is appropriate for maximizing sensitizer loading of DSSC. The film microstructure is less than $\sim 100 \mathrm{~nm}$ and is smaller than the wavelength, so that little scattering is expected [16]. The grain size is uniformly distributed with relatively scanty holes and voids. Fig. 4 also shows the transmittance of the FTO film. An average transmittance of $83 \%$ of FTO film taken in the visible range was measured. This value implies that the film is highly transparent in the visible-UV range. This value shows that the film is highly transparent. High transmittance is significant for DSSC in allowing the movement of incident sunlight down to the active region of DSSC photoanode [20-23].

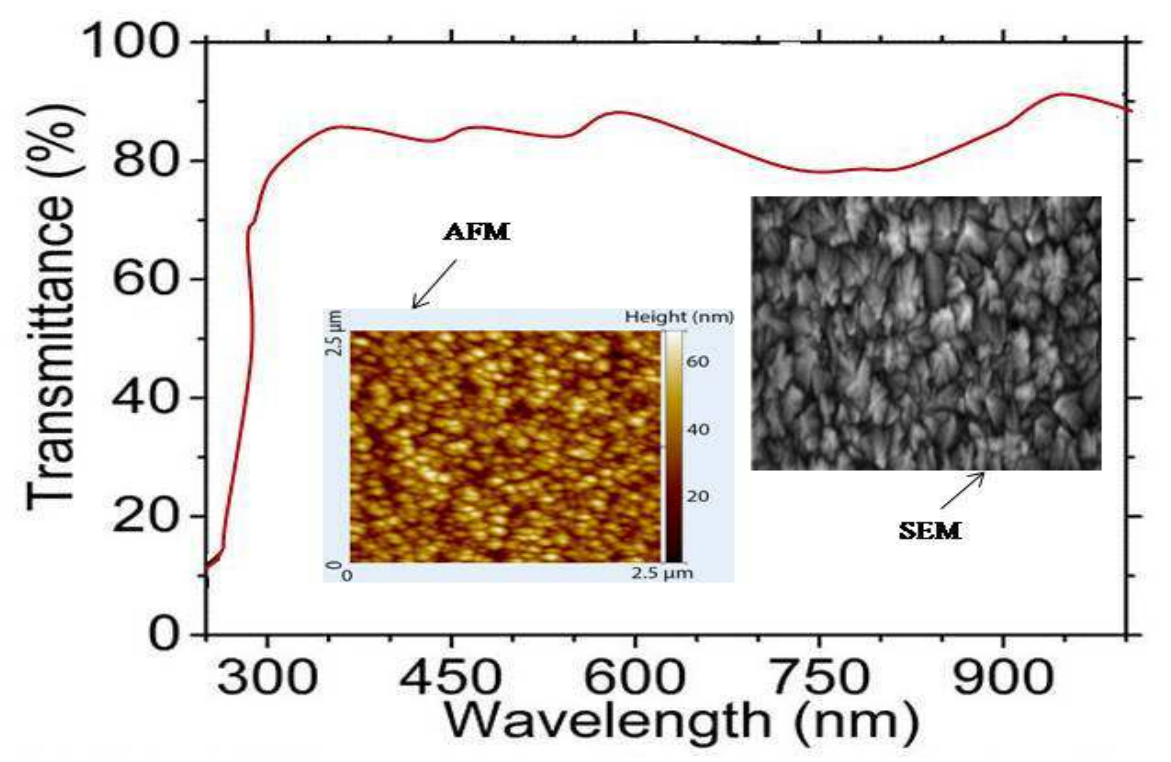

Fig. 4: Transmittance, SEM, and AFM of the FTO films

The absorption coefficient (2) is related to the incident photon energy by: $\alpha \mathrm{h} v=\mathrm{C} .(\mathrm{h} v-\mathrm{Eg})^{1 / 2}$

where $\mathrm{C}$ is a constant, $\mathrm{E}_{\mathrm{g}}$ band gap energy, $\mathrm{h} v$ is the photon energy [24]. Plotting $\alpha \mathrm{h} v^{2}$ against hv and extrapolating the linear portion to zero gives the bandgap of $3.8 \mathrm{eV}$ as shown in Fig. 5. The previous band gap measure with FTO films is within the range of 3.9-4.6 eV [25].

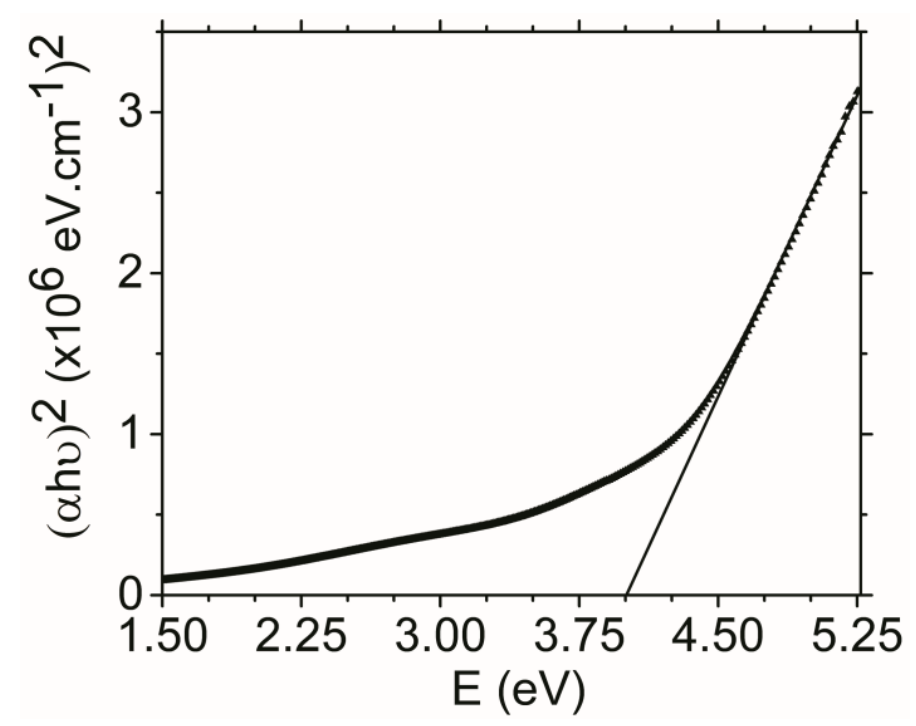

Fig. 5: Plot of (ahv) ${ }^{2}$ as a function of photon energy (hv) to estimate band gap 


\section{Electrical properties}

Table 3 shows the summary of electrical properties of FTO films deposited using the key controlling parameters in table 1 . The average resistivity $(\rho)$ of $6.89 \times 10^{-4}$ was achieved, Hall Effect measurement revealed a carrier concentration $(\mathrm{n})$ value of $1 \times 10^{20}\left(\mathrm{~cm}^{-3}\right)$ while $9.4\left(\mathrm{~cm}^{2} / \mathrm{V}-\mathrm{s}\right)$ was measured as the films' election mobility $(\mu)$. These values show that the FTO film is of high quality and can be a good candidate for DSSC application as seen in the next section.

Table 3: Summary of electrical properties of the FTO samples

\begin{tabular}{llll}
\hline $\boldsymbol{\rho}(\mathbf{\Omega . c m})$ & $\mathbf{n}\left(\mathbf{c m}^{-3}\right)$ & $\boldsymbol{\tau}(\mathbf{\%})$ & $\boldsymbol{\mu ( \mathbf { c m } ^ { 2 } / \mathrm { V } - \mathbf { s } )}$ \\
\hline $6.89 \times 10^{-4}$ & $1 \times 10^{20}$ & 83 & 9.4 \\
\hline
\end{tabular}

\section{Preparation of graphene}

Graphene (GR) is a material with promising photoelectric properties. It has a fast electron transfer, good charge-carrier mobility, and high conductance [26].Therefore; it is adopted here to enhance the performance of the DSSC along with the grown FTO samples. A 7:2 mixture of $98 \%$ of $\mathrm{H}_{2} \mathrm{SO}_{4}$ and phosphoric acid $\left(82 \% \mathrm{H}_{3} \mathrm{PO}_{4}\right)(221: 8 \mathrm{~mL})$ was refrigerated at a temperature of about $4^{\circ} \mathrm{C}$. It was then mixed with about $3.5 \mathrm{~g}$ of graphite flakes and $13.5 \mathrm{~g}$ of $\mathrm{KMnO}_{4}(97 \%)$. The detail of preparation procedure can be found in [27-28]. The solution'" temperature was controlled by cool $320 \mathrm{ml}_{2} \mathrm{O}$ together with $4 \mathrm{~mL}$ hydrogen peroxide. The mixture was centrifuged at 4200 for 5 hours after being washed with distilled water, hydrochloric acid $(\mathrm{HCl})$ and ethanol.

To prepare the $\mathrm{SnO}_{2}-\mathrm{RGO}$ hybrid. The glass beaker containing $85 \mathrm{~mL}$ DI water at $8 \mathrm{mg}$ of GO content was "ultrasonicated" for $3 \mathrm{hrs}$ after which about $1.7 \mathrm{~g}$ of $\mathrm{SnCl}_{2} \cdot 2 \mathrm{H}_{2} \mathrm{O}$ was mixed with $220 \mathrm{~mL}$ of $0.12 \mathrm{M} \mathrm{HCl}$ solution [27-28]. The GO dispersion was mixed with the tin (II) chloride solution and then stirred for 25 minutes. The mixtures were then reacted under $550 \mathrm{~W}$ for 5 minutes. The sample was then incorporated into FTO sample grown in the last section for DSSC photoanode application

\section{Incorporation of grown FTO and graphene as photoanode}

The FTO samples grown above were immersed in a $40 \mathrm{mM}$ of titanium chloride at a temperature of $73^{\circ} \mathrm{C}$. The mixture after being treated with FTO electrodes was coated with the $\mathrm{SnO}_{2}$ and $\mathrm{SnO}_{2}-\mathrm{RGO}$ pastes using a technique known as "doctor blade" [29]. A film thickness of about $16 \mu \mathrm{m}$ was achieved with adhesive scotch tape on the FTO electrode. The optimum condition of photoanode thickness to achieve high DSSC performance is 2-16 $\mu \mathrm{m}$ [30-32]. Both photoanode and counter electrodes were prepared using the high-quality FTO coated with graphene. Another experiment was set up but this time without graphene to study the effect of graphene on the performance of DSSC. After the deposition of $\mathrm{SnO}_{2}$ and $\mathrm{SnO}_{2}$-RGO pastes onto the FTO substrates, the photoanode films were gradually heated under an air flow at $125^{\circ} \mathrm{C}$ for $30 \mathrm{~min}$, followed by cooling to room temperature. For preparing DSSC counter electrode, a hole with a diameter of $7 \mathrm{~mm}$ was drilled on the FTO. Then the FTO glass was washed as described above for FTO working electrode but instead for 6 min. The FTO was heated to $470{ }^{\circ} \mathrm{C}$ for $15 \mathrm{~min}$. Electrolyte iodolyte R-150 was introduced drop by drop through the one side of the two small holes, thereafter, the edges of the two holes were cleaned with acetonitrile and the holes were then sealed with 50:50 amoxil A and B gum, let dry at room temperature. Silver paint was applied on the conducting side of each electrode to ensure optimal electrical connections or contact [33]. The active area was $4.55 \mathrm{~cm}^{2}$. Fig. 6 shows the assembled DSSC solar cells. The effect of graphene incorporation on the photoanode was repeated using photoanode with FTO only (no graphene incorporation). The efficiency of both experiments was calculated using $\mathrm{I}-\mathrm{V}$ characterization discussed in the next section. 


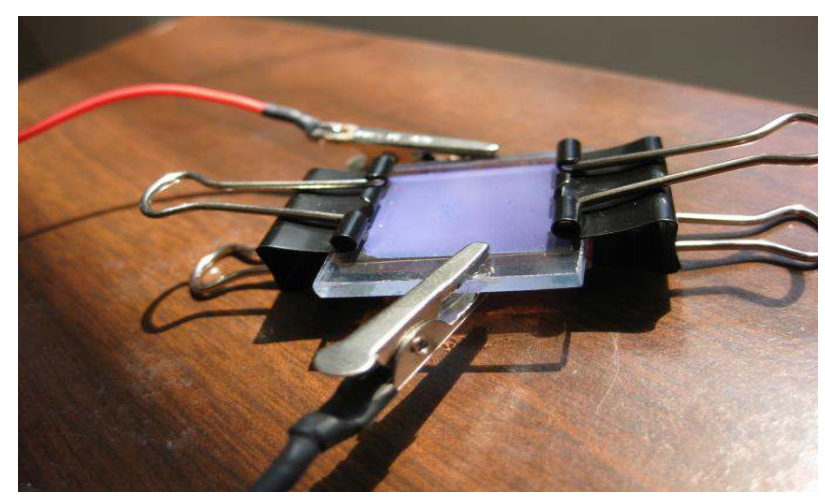

Fig. 6: Images of the DSSCs prototype with $\mathrm{TiO}_{2}$ and FTO electrodes

\section{Measurement of DSSC efficiency}

"The I-V characteristics were recorded by varying an external potential compensating the photovoltage. The integral photocurrent (short-circuit current) was obtained without the external potential. The photoelectric efficiency was calculated with respect to the solar spectra through a calibration of the Light Drive 1000 lamp with direct sunlight" [34].

The overall efficiency $\eta$ of a photovoltaic cell was calculated from the expression:

$\eta=\frac{\mathrm{Jsc}_{\mathrm{oc}} \mathrm{FF}}{\mathrm{P}_{\mathrm{s}}}$ or $\frac{\mathrm{P}_{\text {out }}}{\mathrm{P}_{\text {in }}}$

where $\mathrm{J}_{\mathrm{sc}}$ is the integral photocurrent density (current obtained at the short-circuit condition, divided by the area of the cell), $\mathrm{V}_{\text {oc }}$ is the open circuit voltage, $\mathrm{P}_{\mathrm{s}}$ is the intensity of the incident light. FF is the fill factor (related to the series resistance for a practical solar cell) and was obtained from equation (4). $\mathrm{FF}=\frac{\mathrm{I}_{\mathrm{MP}} \cdot \mathrm{V}_{\mathrm{MP}}}{\mathrm{I}_{\mathrm{SC}} \mathrm{V}_{\mathrm{OC}}}$

The parameters $I_{M P}, V_{M P}, I_{S C}$, and $V_{\text {oc }}$ were obtained from fig. 7 which illustrates the current-voltage characteristics of the prepared DSSC sample with graphene-based FTO and FTO only. Using the information in fig. 7 for the calculation of efficiency, an energy conversion efficiency of $7.98 \%$ at 100 $\mathrm{mW} / \mathrm{cm}^{2}$ light intensity is obtained with graphene incorporated DSSC while the energy conversion of $6.02 \%$ was obtained with only FTO (no graphene incorporation). The difference in efficiency is significant and depicts an improvement in the performance of DSSC. While some reports emphasize that there have not been an acceptable explanation and theories on graphene enhancing role in DSSC, [35] asserted that the enhancement may be attributed to the ultrahigh theoretical surface area of 2600 $\mathrm{m}^{2} / \mathrm{g}$ and high thermal conductivity of $5 \times 10^{3} \mathrm{~W} / \mathrm{m} \mathrm{K}$ of graphene which allows for perfect electron mobility.

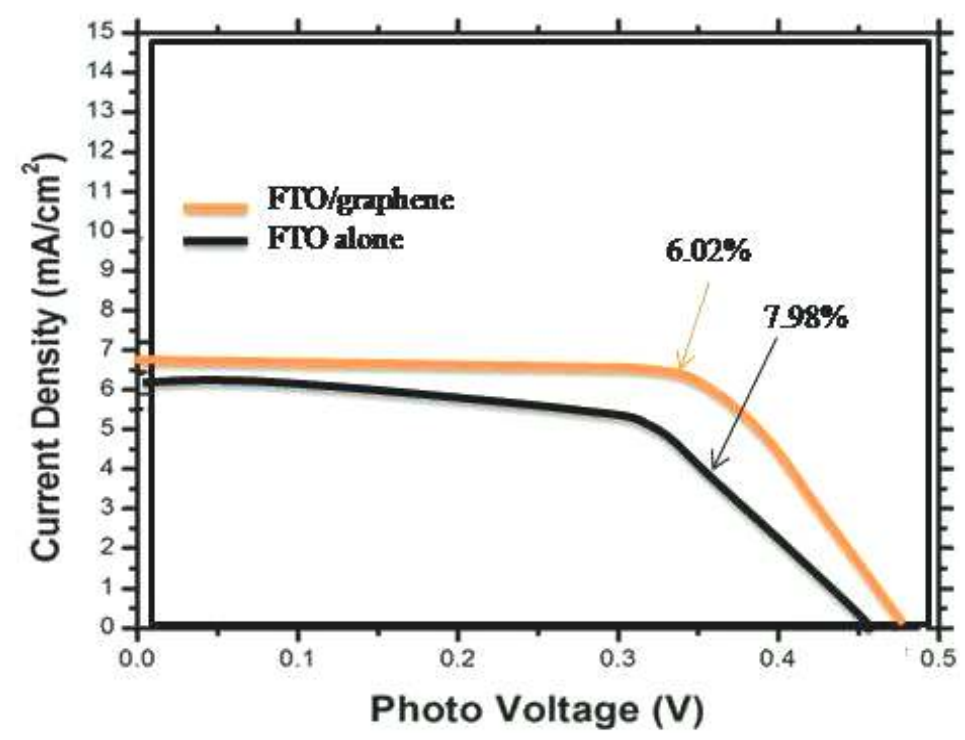

Fig. 7: Current-voltage of both FTO/graphene and FTO alone photoanode 
Furthermore, [41-42] opined that there are many grain boundaries in $\mathrm{TiO}_{2}$ nanoparticle, leading to faster charge recombination at the $\mathrm{TiO}_{2} /$ electrolyte interface. Therefore, low dimensional materials such as carbon nanostructures (carbon nanotube (CNT)) and graphene sheets incorporated into semiconductor electrodes could improve the charge collection and photovoltaic performance of DSSC [43-44].This is because they possess band gaps which could align with those of $\mathrm{TiO}_{2}$ and FTO to produce a more efficient pathway for collection and transport of photogenerated electrons [45-46]. This may be responsible for the increase in performance in graphene-based DSSC in this research.

\section{Conclusion}

This research has demonstrated that incorporation of graphene into DSSC and the usage of highquality FTO thin films could jointly enhance the DSSC efficiency. High-quality FTO thin film samples were first grown with homemade SPEED technique using Tin (II) chloride dihydrate and ammonium fluoride as starting precursors. The first FTO sample (photoelectrode and a counter electrode) was prepared with graphene along with $\mathrm{TiO}_{2}$ while the second FTO samples without graphene were used as a control. The graphene-based DSSC showed an efficiency of $7.98 \%$ whereas the DSSC fabricated without graphene showed a lower efficiency of $6.02 \%$. The higher efficiency obtained when graphene was incorporated could be attributed to the ultrahigh surface area and thermal conductivity of graphene which tend to enhance the charge mobility and photovoltaic performance of DSSC. More research is however required to determine the exact amount of graphene that could achieve optimal DSSC performance. Further studies will also offer an adequate clarification for starting point of the better incorporation of graphene in DSSCs.

\section{References}

[1] Nazeeruddin, M.K.; Kay, A.; Rodicio, I.; Humphry-Baker, R.; Mueller, E.; Liska, P.; 'Vlachopoulos, N.; Graetzel, M. Conversion of light to electricity by cis-X2bis(2,2'-bipyridyl4,4'-dicarboxylate) ruthenium(II) charge-transfer sensitizers $(\mathrm{X}=\mathrm{Cl})$ on nanocrystalline $\mathrm{TiO} 2$ electrodes. J. Am. Chem. Soc.1993, 115, 6382-6390.

[2] Calogero, G.; Di Marco, G.; Cazzanti, S.; Caramori, S.; Argazzi, R.; di Carlo, A.; Bignozzi, C.A. Efficient dye-sensitized solar cells using red turnip and purple wild sicilian prickly pear fruits. Int. J. Mol. Sci.2010, 11, 254-267.

[3] Angel Ramon Hernández-Martínez and Rogelio Rodríguez, Miriam Estévez, Susana Vargas Stabilized Conversion Efficiency and Dye-Sensitized Solar Cells from Beta Vulgaris Pigment Int. J. Mol. Sci.2013, 14, 4081-4093.

[4] O'Regan.B. Gratzel M, Nature 353(1991)737-740.

[5] Yasuo Chiba, Ashraful Islam, Yuki Watanabe, Ryoichi Komiya, Naoki Koide and Liyuan Han., Jpn. J. Appl. Phys. 45 (2006) L638-L640.

[6] Hoik Lee,Tomoki Nagaishi,Duy-Nam Phan,Myungwoong Kim,Ke-Qin Zhang,Kai Wei and Ick Soo Kim. Effect of graphene incorporation in carbonnanofiber decorated with $\mathrm{TiO}_{2}$ for photoanodeapplications.RSC Adv., 2017, 7, 6574.

[7] S. Suhaimi, M. Mohamad S., Z.A. Alahmed, J. Chyský A. H. Reshak. Materials for Enhanced Dye-sensitized Solar Cell Performance. Electrochemical Application. Int. J.Electrochem. Sci., 10 (2015) 2859 - 2871.

[8] Xiaoru Guo ${ }^{1}$, Ganhua $\mathrm{Lu}^{2}$ and Junhong Chen Graphene-Based Materials for Photoanodes in Dye-Sensitized Solar Cells. Front. Energy Res., 2015.

[9] J.T. Wang., X. L., Shi, W. W., Liu, X. H. Zhong, J. N. Wang, L. Pyrah, K. D. Sanderson, P.M. Ramsey, M. Hirata \& K. Tsuri, Influence of Preferred Orientation on the electrical conductivity of Fluorine-Doped Tin Oxide Films. Scientific Reports. 4: 3679 (2014). DOI:10.1038/srep03679.

[10] U. Mehmood, S. U. Rahman, K. Harrabi, I. A. Hussein, and B. V. S. Reddy, Advances inMaterials Science and Engineering, 2014 (6346) (2014) 1-12. 
[11] J.H., Lee, \& B.O., Park. Transparent conducting ZnO: Al, In and Sn thin films deposited by the sol-gel method. Thin Solid Films 426, (2003) 94-99).

[12] J.T. Wang., X. L., Shi, W. W., Liu, X. H. Zhong, J. N. Wang, L. Pyrah, K. D. Sanderson, P.M. Ramsey, M. Hirata \& K. Tsuri, Influence of Preferred Orientation on the electrical conductivity of Fluorine-Doped Tin Oxide Films. Scientific Reports. 4: 3679 (2014). DOI:10.1038/srep03679.

[13] E., Elangovan, M.P., Singh, K., Ramamurthy. Studies on structural and electrical properties of spray deposited $\mathrm{SnO}_{2}$ : F thin films as a function of film thickness Solar cell Materials. Mater. Sci. Eng. B 113 (2004) 143.

[14] C. Agashe, J. Hüpkes, G., Schöpe, \& M. Berginski, Physical properties of highly oriented spray-deposited fluorine-doped tin dioxide films as a transparent conductor. Sol. Energy Mater. Sol. Cells 93, (2009) 1256-1262.

[15] D.H., Zhang \& H. L. Ma. Scattering mechanisms of charge carriers in transparent conducting oxide films. Appl. Phys. A 62, (1996) 487-492).15

[16] F., Khalilzadeh-Rezaie, I.O. Oladeji, G.T., Yusuf, J. Nath, N., Nader, S., Vangala, J.W. Cleary, W. V., Schoenfeld, \& R.E., Peale. Optical and Electrical Properties of Tin OxideBased Thin Films Prepared by Streaming Process for Electrodeless Electrochemical Deposition. MRS Spring Meeting, (2015) MRSS15-2136423.R1.

[17] I.O. Oladeji, Film growth system and method, in, US Patent, (2010).

[18] Ibiyemi Abideen, Yusuf Gbadebo and Faremi Abbas Substrate temperature effect on the photophysical and microstructural properties of fluorine-doped tin oxide nanoparticles, $2017 \mathrm{~J}$. Semicond. 38072001.

[19] Ch. Sujatha, G. Mohan Rao, S. Uthanna, Characteristics of indium tin oxide films deposited by bias magnetron sputtering, Mater. Sci. Eng. B. 94 (2002), 106- 110.

[20] A. Stadler, Materials, Transparent conducting oxides- An up-to-date overview, Materials 5 (2012), 661-683.

[21] D. Miao, Q. Zhao, S. Wu, Z. Wang, X. Zhang, X. Zhao, Effect of substrate temperature on the crystal growth orientation of $\mathrm{SnO}_{2}$ : F thin films spray-deposited on glass substrates, J. NonCrystalline Solids 356 (2010), 2557-2561.

[22] R. Riveros, E. Romero and G. Gordillo, Synthesis and Characterization of Highly Transparent and Conductive $\mathrm{SnO}_{2}$ : F and $\mathrm{In}_{2} \mathrm{O}_{3}$ : Sn thin Films Deposited by Spray Pyrolysis, Braz. J. Phys. 36 (2006), 1042-1045.

[23] A. Smith, J.M. Laurant, D.S. Smith, J.P. Bonnet, R.R. Clemente, Synthesis and Characterization of Highly Transparent and Conductive SnO2: F and In2O3: Sn thin Films Deposited by Spray Pyrolysis, Thin Solid Films 266 (1995), 20-30.

[24] T. S. Moss, Optical Properties of semiconductors, Butterworth, London, (1961) 15-37.

[25] D. S.Zhang, T.Yoshida, K.Furuta, H.Minoura J.Photochem. Photobiol. A: Chem.164 (2004)159- 166.

[26] Seong-Bum Kim, Jun-Yong Park, Chan-Soo Kim, Kikuo Okuyama Sung-Eun Lee,

Hee-Dong Jang and Tae-Oh Kim. Effects of Graphene in Dye-Sensitized Solar Cells Based on Nitrogen-Doped $\mathrm{TiO}_{2}$ Composite.J. Phys. Chem. C, 2015, 119 (29), pp 16552-16559.

[27] M. Batmunkh, M.J. Biggs, J.G. Shapter, Carbon Nanotubes for Dye-Sensitized Solar Cells. Small, 11 (2015) 2963-2989.

[28] D.C. Marcano, D.V. Kosynkin, J.M. Berlin, A. Sinitskii, Z. Sun, A. Slesarev, L.B. Alemany, W. Lu, J.M. Tour, Improved Synthesis of Graphene Oxide, ACS Nano, 4 (2010) 4806-4814.

[29] Dae-Kue Hwang, Byunghong Lee and Dae-Hwan Kim. Efficiency Enhancement in Solid DyeSensitized Solar Cell by Three-Dimensional Photonic CrystalElectronic Supplementary Material (ESI) for RSC Advances (2013).

[30] M. Batmunkh, M. Dadkhah, C.J. Shearer, M.J. Biggs, J.G. Shapter, Tin oxide light scattering layer for titania photoanodes in dye-sensitized solar cells, Energy Technology, 4 (2016) DOI: 10.1002/ente.201600008.

[31] L. Yang, W.W.-F. Leung, Electrospun $\mathrm{TiO}_{2}$ Nanorods with Carbon Nanotubes for Efficient Electron Collection in Dye-Sensitized Solar Cells, Advanced Materials, 25 (2013) 1792-1795. 
[32] S. Ito, T.N. Murakami, P. Comte, P. Liska, C. Grätzel, M.K. Nazeeruddin, M. Grätzel, Fabrication of thin film dye sensitized solar cells with solar to electric power conversion efficiency over 10\%, Thin Solid Films, 516 (2008) 4613-4619.

[33] G. R. A. Kumara, S. Kaneko, M. Okuya, and K. Tennakone Langmuir 18(26)(2002) 10493-10495.

[34] Q.-B. Meng, K. Takahashi, X.-T. Zhang, I. Sutanto, T. N. Rao, O. Sato, A. Fujishima Langmuir 19(9)(2003) 3572-3574.

[35] Bard, Allen J.; Faulkner, Larry R. (2000-12-18). Electrochemical Methods: Fundamentals and Applications Wiley. 2 ed.

[36] N.G. Park, K.M., Kim, M.G. Kang, K.S.Ryu, S.H. Chang, Y.J., Shin, Adv.Mater.17(2005)2349-2353.

[37] Beili Pang, Lifeng Dong, Shuai Ma, Hongzhou Dong and Liyan Yu(2016). Performance of FTO-free conductive graphene-based counter electrodes for dye-sensitized solar cells. RSC advances Issue 472016.

[38] Casaluci S, Gemmi M, Pellegrini V, Di Carlo A, Bonaccorso F Graphene-based large area dyesensitized solar cell modules, RSC advances, Issue 9, 2016.

[39] Azar Pishdar and Mahmoud Samadpour $\mathrm{TiO}_{2} /$ Graphene Nanocomposites for Enhancing the Performance of Dye-Sensitized Solar Cells, Vol. 13, Issue. 1 Pages $84-91$.

[40] Dingwen Zhang, Milton Wang, Alexandre G Brolo, Jie. Shen, Xiaodong Li and Sumei Huang.Enhanced performance of dye-sensitized solar cells using gold nanoparticles modified fluorine tin oxide electrode (2013) IOP Publishing Ltd.

[41] J. van de Lagemaat, N.-G. Park and A. Frank, J. Phys. Chem. B, 2000, 104, 2044-2052.

[42] M. Cass, A. B. Walker, D. Martinez and L. Peter, J. Phys.Chem. B, 2005, 109, 5100-5107.

[43] B. Liu and E. S. Aydil, J. Am. Chem. Soc., 2009, 131,3985-3990.

[44] S. H. Kang, S. H. Choi, M. S. Kang, J. Y. Kim, H. S. Kim, T. Hyeon, and Y. E. Sung, Adv. Mater., 2008, 20,54-58.

[45] N. Yang, J. Zhai, D. Wang, Y. Chen and L. Jiang, ACS Nano,2010, 4, 887-894.

[46] C.-Y. Yen, Y.-F. Lin, S.-H. Liao, C.-C. Weng, C.-C. Huang, Y.-H. Hsiao, C.-C. M. Ma, M.C. Chang, H. Shao andM.-C. Tsai, Nanotechnology, 2008, 19, 375305.

[47] J. Durantini, P. P. Boix, M. Gervaldo, G. M. Morales, L. Otero, J. Bisquert and E. M. Barea, J. Electroanal. Chem., 2012, 683,43-46.

[48] A.O.; Awodugba, G.T. Yusuf. Substrate -Nozzle Distance (SND) Influence on the Properties of Fluorine-Doped Tin Oxide Thin Films. Preprints 2017, 2017120043 (doi: 10.20944/preprints201712.0043.v1).

[49] A.O.; Awodugba, G.T. Yusuf Effects of Water Concentration on the Structural and Optical Properties of FTO Thin Films Grown at Home Made SISOM'S SPEED Technique. Preprints 2017, 2017110188 (doi: 10.20944/preprints201711.0188.v1).

[50] A.O.; Awodugba, G.T. Yusuf. Effects of Water Addition on the Structural and Electrical Properties of FTO Thin Films Deposited by Homemade Spray Pyrolysis. International Journal of Advancement In Engineering Technology, Management and Applied Science Volume 04 Issue 11, 103-113. 